\title{
Desire for tooth bleaching and treatment performed in Brazilian adults: findings from a birth cohort
}

\begin{abstract}
Fernando Barcellos da SILVA ${ }^{(a)}$ Luiz Alexandre CHISINI(a) Flávio Fernando DEMARCO ${ }^{(a)}$ Bernardo Lessa HORTA(b) Marcos Britto CORREA(a)
\end{abstract}

(a) Universidade Federal de Pelotas UFPEL, Graduate Program in Dentistry, Pelotas, RS, Brazil.

(b) Universidade Federal de Pelotas - UFPEL, Graduate Program in Epidemiology, Pelotas, RS, Brazil.

Declaration of Interests: The authors certify that they have no commercial or associative interest that represents a conflict of interest in connection with the manuscript.

Corresponding Author:

Marcos Britto Correa

E-mail: marcosbrittocorrea@hotmail.com

\begin{abstract}
Population-based studies estimating the prevalence of tooth bleaching desire or the percentage of individuals who had performed this treatment are rare. Thus, the aim of this study was to evaluate the desire to perform tooth bleaching and the prevalence of adult individuals who had performed the treatment and investigate the association of these outcomes. A subsample $(n=536)$ of the 1982 Pelotas birth cohort in southern Brazil was investigated at the ages 15, 24 and 31 by clinical examinations and interviews. The prevalence of bleaching at 31 years was $15.6 \%$ [95\%CI 12.6-18.9] while 85.9\% [95\%CI 82.7-88.7] reported they desired the treatment. Multivariate Poisson regression analysis showed that individuals who have visited the dentist within the last year showed a treatment prevalence ratio (PR) 2.31 times [95\%CI 1.40-3.83] higher compared with those who had the last dental visit more than a year before the interview. Similarly, individuals with smoking habits presented an elevated PR of 1.60 [95\%CI 1.00-2.55], and the low-income trajectory group showed the largest PR of desire for tooth bleaching (1.17 [95\%CI 1.07-1.28]). Moreover, individuals from the high-risk caries trajectory group presented a higher prevalence of desire for tooth bleaching than individuals from low caries trajectory group. Individuals who have declared being "dissatisfied" with their dental color presented a prevalence of desire for tooth bleaching $16 \%$ greater than "satisfied" ones. Thus, the present findings confirm that tooth bleaching has become a frequently desired dental treatment to improve dental aesthetics in the population and a considerable rate of adults has performed the treatment.
\end{abstract}

Keywords: Tooth Bleaching; Epidemiology; Esthetics, Dental.

\section{Introduction}

Dental discoloration is a prevalent condition affecting different age groups that can be induced by diseases or by the natural process of dental senescence. ${ }^{1,2}$ Despite not being a disease that directly compromises the health of individuals, the presence of tooth darkening can influence relationships and induce a negative self-image. ${ }^{3,4}$ Besides, bleaching has been reported to lead to psychological influences ${ }^{5}$ and improve oral health related quality of life in patients who underwent at-home vital bleaching. ${ }^{6}$ 
Esthetic concepts are increasing in the present society resulting in a growing demand for esthetic procedures. ${ }^{78}$ Patients are not only willing to present a well-aligned smile, but also requesting whiter teeth, thus dental bleaching treatments have become more popular. ${ }^{9}$ Different methods of dental bleaching are available for patients and clinicians, including overthe-counter products, at-home products used under the supervision of the dentist, and in-office products, with most containing different concentrations of hydrogen or carbamide peroxide. ${ }^{10}$ Generally, except for some over-the-counter (OTC) products, bleaching agents are effective, improving tooth color with few side effects, especially considering at-home treatments for vital teeth with low agent concentration.,11,12

The advertised results associated with the growing demand for esthetics induce patients to desire dental bleaching and leading dentists to be more prone to offer and perform the treatment. ${ }^{13,14,15}$ However, the influence of socioeconomic and environmental factors on both the desire and the accomplishment of dental bleaching is unknown. The economic and social condition influence the recommendation and option for treatments ${ }^{16,17}$ and can be a decisive component in the choice and desire for dental bleaching. In addition, people with habits that can pigment the teeth like smoking could be more likely to perform whitening, since their teeth may become darker with the continuity of the habit, contributing thus to an elevated prevalence of bleaching.

Despite studies suggesting that tooth bleaching is a treatment commonly desired by patients, there is only one population-based study estimating the prevalence of tooth bleaching desire ${ }^{18}$ and no study investigating the percentage of individuals who had performed these treatments at a population level. Also, it would be interesting to determine the factors that account for dental bleaching treatment. Therefore, the aim of the present study was to evaluate the desire to perform tooth bleaching and the prevalence of adult individuals who had performed the treatment in a birth cohort. The association of these outcomes with demographic, socioeconomic, behavioral, oral health and aesthetic perception variables was also investigated.

\section{Methodology}

This study followed the STROBE statement (Strengthening the Reporting of Observational Studies in Epidemiology). Pelotas is a medium sized city, located in southern Brazil, near the border with Uruguay. In 1982, all the infants born at three maternity hospitals in the city were identified. The 5,914 liveborn infants were measured and their mothers were interviewed at birth and at several follow-ups; detailed information about the methods of this cohort study is available elsewhere. ${ }^{19,20}$

In 1997, a representative sample of the cohort's 900 adolescents was selected to take part in the first Oral Health Study (OHS-97), which consisted of dental examinations and an interview. The 888 adolescents were contacted again in 2006 for another oral health study (OHS-06), of which 720 individuals were found. In 2013, when the participants were 31 years old, a new oral health study was performed (OHS-13). The 888 individuals that have participated in the first OHS were contacted. This study consisted of an oral examination and an interview, including oral health habits and self-perception of oral conditions.

\section{Outcome variables}

For this study, two outcomes were used: a) performed tooth bleaching treatments; $b$ ) desire to undergo tooth bleaching. The information was obtained using two questions: "Have you already performed a bleaching treatment to whiter your teeth?" and "Would you wish to perform a treatment to white your teeth?". Both outcomes were collected in a dichotomous manner (yes/no).

\section{Independent variables}

Independent variables were collected in different assessments of the Oral Health Studies. The groupbased trajectory modelling was utilized to identify the groups of individuals with similar trajectory of income measured in four time points (at birth, OHS-97, OHS06 and OHS-13). Individuals were asked about their income, which was collected in a continuous variable in Brazilian reals (BRL) and categorized in tertiles. Thus, the models were estimated with the command "traj" in the Stata $12.0^{21}$ to identify the similarity of income 
trajectory between the individuals. The parameters for the trajectory model were determined based on the maximum likelihood of the Newton method. ${ }^{22,23}$ The selection of the model considered the estimate for latent number of categories and the order of polynomial for each latent trajectory. The number of trajectories was determined when the sequential comparisons of the Bayesian information criterion (BIC) and their adjusted criterion between the model with $\mathrm{K}$ and $\mathrm{K}+1$ trajectories yielded no further substantial difference in the BIC score than the $k+1$ model. Thus, the BIC for income trajectory supported three trajectory groups (high, downward and low trajectory). Trajectory for caries was performed similarly. The D component of the DMFT (decayed, missing, and dilled teeth) index was collected in three points (OHS-97, OHS-06 and OHS-13) and considered to estimate caries trajectory. The analysis of caries variables supported a model with two groups of trajectory, being nominated as "high" and "low" caries risk.

Other independent variables that were used in this study were collected in OHS-13. Time since last dental visit was collected in years and dichotomized in "up to 1 year" and "more than 1 year". Type of service where individuals had the last dental visit was also collected and categorized in public, private health insurance, and out-of-pocket.

Smoking habit was also collected at age 30 . Individuals who have declared smoking at least one cigarette per week were classified as "smokers". "Self-perception about dental appearance and teeth color was collected in a 5 grade Likert scale by the questions: "Considering the appearance of your teeth, are you..." and "Considering the color of your teeth, are you..." and dichotomized in "Satisfied" (very satisfied, satisfied, neither satisfied nor dissatisfied) and "dissatisfied" (dissatisfied and very dissatisfied).

The fieldwork team comprised six dentists and interviewers that were trained for questionnaire application. Questionnaire was pre-tested before the start of the study in order to evaluate the comprehension of the instrument in a sample of 20 adults from different socioeconomic status. During the study, $10 \%$ of the sample was re-interviewed with a short version of the questionnaire for quality control. The fieldwork was carried out between October 2013 and January 2014.
Losses were considered when the contact (by phone and e-mail) with cohort members was not possible and the individual was not found after three visits in different periods of the day in their household.

\section{Data analysis}

Data were entered in an electronic spreadsheet and analyzed using the software Stata 12.0. Descriptive analysis was performed to assess the prevalence of the outcomes. The association of outcomes with independent variables was evaluated in bivariate way by chi-square test. Multivariate Poisson regression models have been proposed to estimate prevalence ratios of binary outcomes in cross-sectional studies. In the present study, Poisson Regression was used to assess the association of both outcomes with exposure variables, adjusting by possible confounders. ${ }^{24}$ The entrance of variables on the model was determined by a theoretical hierarchical model described in Figure. Socioeconomic and demographic variables were placed on more distal positions, followed by behavioral characteristics. Self-perception of individuals' dental color and appearance were positioned in the most proximal block. Each variable was adjusted for variables from the same and upper blocks of the model. Prevalence ratios and 95\% confidence intervals were estimated from the models.

\section{Ethical issues}

This project was approved by the UFPel Ethics Committee. All the examinations and interviews were performed with individual authorization after participants signed informed consent forms. Individuals who had treatment needs were identified and referred for treatment.

\section{Results}

A total of 536 individuals answered the questionnaire in 2013, representing a $60.4 \%$ response rate compared to the first study of oral health conducted in 1997. The number of refusals represented nearly $5 \%$ of the original sample while losses totalized $34 \%$. Individuals wishing to undergo tooth bleaching were 85.9\% (95\% CI: 82.7-88.7), while $15.6 \%$ (12.6-18.9) had underwent bleaching treatment. 
In the bivariate analysis of factors associated with the outcomes (Table 1), an association of time since the last dental visit with carrying out bleaching was observed. Individuals who had the last dental visit in the last 12 months presented a higher prevalence of having had bleaching treatment. Regarding the

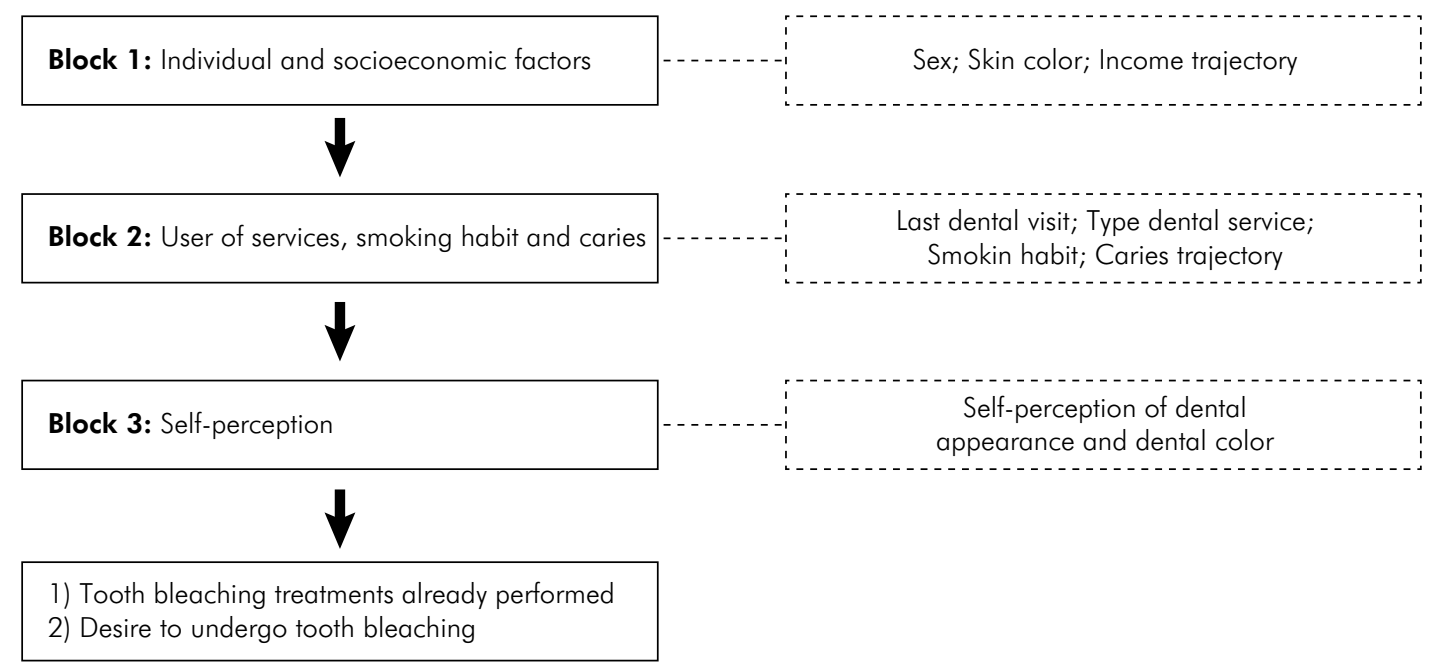

Figure. Theoretical model for analysis of desiring and having performed dental bleaching and independent variables.

Table 1. Bivariate analysis of outcomes according to independent variables in adults from 1982 Pelotas birth cohort ( $\mathrm{n}=536$ ).

\begin{tabular}{|c|c|c|c|c|}
\hline Independent variables & Dental bleaching & $p$-value & Desire for dental bleaching & $\mathrm{p}$-value \\
\hline \multicolumn{5}{|l|}{ Sex } \\
\hline Male & $35(13.0)$ & \multirow{2}{*}{0.100} & $219(83.6)$ & \multirow{2}{*}{0.113} \\
\hline Female & $48(18.2)$ & & $222(88.5)$ & \\
\hline \multicolumn{5}{|l|}{ Income trajectory } \\
\hline High & $43(19.2)$ & \multirow{3}{*}{0.139} & $173(79.7)$ & \multirow{3}{*}{0.001} \\
\hline Downward & $30(13.1)$ & & $193(89.4)$ & \\
\hline Low & $10(12.6)$ & & $75(93.6)$ & \\
\hline \multicolumn{5}{|l|}{ Last dental visit } \\
\hline More than 1 year & $17(7.3)$ & \multirow{2}{*}{$<0.001$} & $191(88.4)$ & \multirow{2}{*}{0.214} \\
\hline Up to 1 year & $66(22.8)$ & & $241(84.6)$ & \\
\hline \multicolumn{5}{|l|}{ Type of dental service } \\
\hline Public & $11(9.2)$ & \multirow{3}{*}{0.052} & $92(91.1)$ & \multirow{3}{*}{0.140} \\
\hline Private health insurance & $16(15.2)$ & & $91(88.4)$ & \\
\hline Out of pocket & $56(18.9)$ & & $247(83.7)$ & \\
\hline \multicolumn{5}{|l|}{ Caries trajectory } \\
\hline Low & $69(17.1)$ & \multirow{2}{*}{0.077} & $322(83.4)$ & \multirow{2}{*}{0.004} \\
\hline High & $14(10.7)$ & & 119 (93.7) & \\
\hline \multicolumn{5}{|l|}{ Smoking habit at 30 years } \\
\hline No & $56(14.3)$ & \multirow{2}{*}{0.150} & 322 (85.9) & \multirow{2}{*}{0.611} \\
\hline Yes & $19(20.2)$ & & $80(87.9)$ & \\
\hline \multicolumn{5}{|c|}{ Self-perception of dental appearance } \\
\hline Satisfied & $51(14.3)$ & \multirow{2}{*}{0.238} & $316(83.6)$ & \multirow{2}{*}{0.010} \\
\hline Dissatisfied & 32 (18.9) & & $125(92.6)$ & \\
\hline \multicolumn{5}{|c|}{ Self-perception of dental color } \\
\hline Satisfied & $51(14.3)$ & \multirow{2}{*}{0.238} & $272(80.7)$ & \multirow{2}{*}{$<0.001$} \\
\hline Dissatisfied & $32(18.2)$ & & $169(96.0)$ & \\
\hline
\end{tabular}


desire to perform dental bleaching, individuals from the lowest income trajectory presented a higher desire similarly to those who presented a high risk caries trajectory. In addition, individuals dissatisfied with their teeth color and those with worse self-perception of dental appearance also presented a greater prevalence of desire to perform tooth bleaching.

Table 2 shows the results of crude and adjusted analyses for factors associated to having performed bleaching treatment. After adjustments, the time since last dental visit, smoking habit and self-perception of tooth color were associated with this variable. Individuals who have visited the dentist within the last one year showed a $131 \%$ higher prevalence of treatment compared with those who carried out the last dental visit more than a year before the interview. In addition, individuals with smoking habits presented a $60 \%$ higher prevalence of having performed tooth bleaching compared with no smokers. Similarly, individuals who declared being "dissatisfied" with

Table 2. Crude (c) and adjusted (a) prevalence ratios (PR) for factors associated with tooth bleaching in individuals from 1982 Pelotas birth cohort $(n=536)$. Poisson regression analysis.

\begin{tabular}{|c|c|c|c|c|}
\hline Independent variables & $\mathrm{PR}^{c}(95 \% \mathrm{Cl})$ & $\mathrm{p}$-value & $\mathrm{PR}^{a}(95 \% \mathrm{Cl})$ & p-value \\
\hline \multicolumn{5}{|c|}{-2 log likelihood (Empty model) $=475.01816$} \\
\hline \multicolumn{5}{|c|}{ Block 1} \\
\hline \multicolumn{5}{|l|}{ Sex } \\
\hline Male & 1 & \multirow{2}{*}{0.099} & 1 & \multirow{2}{*}{0.069} \\
\hline Female & $1.04(0.93-2.09)$ & & $1.38(0.89-2.14)$ & \\
\hline \multicolumn{5}{|l|}{ Income trajectory } \\
\hline High & 1 & \multirow{3}{*}{0.141} & 1 & \multirow{3}{*}{0.106} \\
\hline Downward & $0.68(0.44-1.04)$ & & $0.66(0.43-1.02)$ & \\
\hline Low & $0.64(0.33-1.21)$ & & $0.62(0.32-1.18)$ & \\
\hline \multicolumn{5}{|c|}{-2 likelihood $($ Block 1) $=468.77846$} \\
\hline \multicolumn{5}{|c|}{ Block 2} \\
\hline \multicolumn{5}{|l|}{ Last dental visit } \\
\hline More than 1 year & 1 & \multirow{2}{*}{$<0.001$} & 1 & \multirow{2}{*}{0.001} \\
\hline Up to 1 year & $3.12(1.88-5.18)$ & & $2.31(1.40-3.83)$ & \\
\hline \multicolumn{5}{|l|}{ Type of dental service } \\
\hline Public free & 1 & \multirow{3}{*}{0.067} & 1 & \multirow{3}{*}{0.504} \\
\hline Private health insurance & $1.64(0.80-3.39)$ & & $1.36(0.72-2.55)$ & \\
\hline Out of pocket & $2.03(1.10-3.75)$ & & $1.36(0.72-2.55)$ & \\
\hline \multicolumn{5}{|l|}{ Caries trajectory } \\
\hline Low & 1 & \multirow{2}{*}{0.087} & 1 & \multirow{2}{*}{0.330} \\
\hline High & $0.62(0.36-1.07)$ & & $0.76(0.44-1.32)$ & \\
\hline \multicolumn{5}{|l|}{ Smoking habit at 30 years } \\
\hline No & 1 & 0.144 & 1 & 0.050 \\
\hline Yes & $1.41(0.88-2.26)$ & & $1.60(1.00-2.55)$ & \\
\hline \multicolumn{5}{|c|}{-2 likelihood (Block $1+$ Block 2) $=403.715$} \\
\hline \multicolumn{5}{|c|}{ Block 3} \\
\hline \multicolumn{5}{|c|}{ Self-perception of dental appearance } \\
\hline Satisfied & 1 & \multirow{2}{*}{0.324} & 1 & \multirow{2}{*}{0.339} \\
\hline Dissatisfied & $0.79(0.49-1.26)$ & & $0.77(0.44-1.32)$ & \\
\hline \multicolumn{5}{|c|}{ Self-perception of dental color } \\
\hline Satisfied & 1 & \multirow{2}{*}{0.236} & 1 & \multirow{2}{*}{0.030} \\
\hline Dissatisfied & $1.27(0.85-1.91)$ & & $1.63(1.05-2.52)$ & \\
\hline \multicolumn{5}{|c|}{-2 likelihood (Block $1+$ Block $2+$ Block 3) $=400.2285$} \\
\hline
\end{tabular}


their teeth color presented a prevalence of having performed tooth-bleaching $63 \%$ higher than those who declared being satisfied with tooth color.

Table 3 shows the results of crude and adjusted analyzes for factors associated with the desire to perform dental bleaching. After adjustments, the final model showed that individuals from the low-income trajectory group had a prevalence of desire for tooth bleaching $17 \%$ greater than those from the highincome trajectory group. Moreover, individuals from the high-risk caries trajectory group presented a higher prevalence of desire for tooth bleaching than individuals from the low caries trajectory group. Similarly, individuals who have declared being

Table 3. Crude (c) and adjusted (a) prevalence ratios (PR) for factors associated with desire for tooth bleaching in individuals from 1982 Pelotas birth cohort $(\mathrm{n}=536)$. Poisson regression analysis.

\begin{tabular}{|c|c|c|c|c|}
\hline Independent variables & $\mathrm{PR}^{\mathrm{c}}(95 \% \mathrm{Cl})$ & $\mathrm{p}$-value & $\mathrm{PR}^{a}(95 \% \mathrm{Cl})$ & $\mathrm{p}$-value \\
\hline \multicolumn{5}{|c|}{-2 log likelihood (Empty model) = 1, 015.38572} \\
\hline \multicolumn{5}{|l|}{ Block 1} \\
\hline \multicolumn{5}{|l|}{ Sex } \\
\hline Male & 1 & \multirow{2}{*}{0.113} & & \multirow{2}{*}{0.197} \\
\hline Female & $1.06(0.99-1.14)$ & & $1.05(0.98-1.12)$ & \\
\hline \multicolumn{5}{|l|}{ Income trajectory } \\
\hline High & 1 & \multirow{3}{*}{0.001} & 1 & \multirow{3}{*}{0.002} \\
\hline Downward & $1.12(1.03-1.22)$ & & $1.12(1.03-1.21)$ & \\
\hline Low & $1.18(1.08-1.28)$ & & $1.17(1.07-1.28)$ & \\
\hline \multicolumn{5}{|c|}{-2 likelihood $($ Block 1) = 1,013.31846 } \\
\hline \multicolumn{5}{|l|}{ Block 2} \\
\hline \multicolumn{5}{|l|}{ Last dental visit } \\
\hline More than 1 year & 1 & \multirow{2}{*}{0.206} & 1 & \multirow{2}{*}{0.382} \\
\hline Up to 1 year & $0.96(0.89-1.03)$ & & $0.97(0.90-1.04)$ & \\
\hline \multicolumn{5}{|l|}{ Type of dental service } \\
\hline Public free & 1 & \multirow{3}{*}{0.101} & 1 & \multirow{3}{*}{0.240} \\
\hline Private health insurance & $0.92(0.85-0.99)$ & & $1.04(0.94-1.15)$ & \\
\hline Out of pocket & $0.97(0.88-1.07)$ & & $0.97(0.88-1.06)$ & \\
\hline \multicolumn{5}{|l|}{ Caries trajectory } \\
\hline Low & 1 & \multirow{2}{*}{$<0.001$} & 1 & \multirow{2}{*}{0.014} \\
\hline High & $1.12(1.05-1.20)$ & & $1.09(1.02-1.17)$ & \\
\hline \multicolumn{5}{|l|}{ Smoking habit at 30 years } \\
\hline No & 1 & \multirow{2}{*}{0.594} & 1 & \multirow{2}{*}{0.979} \\
\hline Yes & $1.02(0.94-1.12)$ & & $1.00(0.91-1.09)$ & \\
\hline \multicolumn{5}{|c|}{-2 likelihood (Block $1+$ Block 2) = 894.24588 } \\
\hline \multicolumn{5}{|l|}{ Block 3} \\
\hline \multicolumn{5}{|c|}{ Self-perception of dental appearance } \\
\hline Satisfied & 1 & \multirow{2}{*}{0.002} & 1 & \multirow{2}{*}{0.357} \\
\hline Dissatisfied & $1.11(1.04-1.18)$ & & $0.96(0.87-1.05)$ & \\
\hline \multicolumn{5}{|c|}{ Self-perception of dental color } \\
\hline Satisfied & 1 & \multirow{2}{*}{$<0.001$} & 1 & \multirow{2}{*}{$<0.001$} \\
\hline Dissatisfied & $1.19(1.12-1.26)$ & & $1.16(1.07-1.25)$ & \\
\hline-2 likelihood (Block $1+$ Block 2 & $=892.74292$ & & & \\
\hline
\end{tabular}


"dissatisfied" with their dental color presented a prevalence of desire for tooth bleaching $16 \%$ greater compared to satisfied individuals.

\section{Discussion}

To the best of our knowledge, this is the first population-based study to investigate not only the prevalence of individuals who underwent tooth bleaching, but also the prevalence of the desire to perform this treatment. A high proportion (85\%) of the surveyed adult population have the desire to perform tooth bleaching, while $15 \%$ had underwent bleaching treatment, which is in line with the increasing demand for esthetic dental treatments, ${ }^{9,13}$ and their popularization.

The high prevalence of the desire to undergo tooth bleaching can be due to the high concern of the Brazilian population about not only dental esthetics, but also general esthetic appearance. Brazil is one of the countries with the highest number of performed plastic surgeries. ${ }^{25}$ Concerns about general esthetics could obviously have an impact on dental esthetics, as the smile is an important component of individuals' appearance. The clinical effectiveness with low level of adverse effects of vital at-home bleaching is reported in several systematic reviews ${ }^{11,26,27}$ The efficacy of in-office tooth bleaching and its relatively low cost compared to other treatment alternatives (composite or ceramic veneers) to recover the color in darkened teeth ${ }^{11,26,27}$ are other reasons for the popularity of bleaching among patients. ${ }^{6,9,10}$ These findings corroborate with previous studies reporting a high prevalence of the desire to perform bleaching in adult populations. ${ }^{10,12}$

Desire for tooth bleaching was greater in individuals from downward and low income trajectory group. This might have been found because dental bleaching could increase the esthetic perception with a positive psychosocial impact and improve the quality of life. ${ }^{5,6}$ Thus, individuals with a low income trajectory can perceive dental whitening as a way to compensate for social deprivations and improve their esthetic perceptions as an approach to minimize their unfavorable social condition. White smiles are linked with physical attractiveness resulting in greater feeling of happiness, ${ }^{28}$ explaining the high desire of these individuals for dental bleaching even when presenting unfavorable oral health conditions. On the other hand, it is likely that individuals with low socioeconomic status have less access to aesthetic treatments, increasing their desire to perform it. Although a tendency for a lower prevalence of having undergone tooth whitening was observed in lower socioeconomic groups, this association was not significant.

A higher desire for dental bleaching was observed also in individuals with high caries trajectory. It is important to highlight that to perform caries trajectory analysis only the decayed component of DMFT was used. Therefore, the participants classified as high risk for caries presented with decayed teeth in all three time points assessed. The elevate desire for dental bleaching in these individuals can reflect an unconscious aspiration to search for access to oral health services or perhaps a false sense of having the possibility to improve their oral health. Individuals with worse social conditions have less access to the health services ${ }^{29,30,31}$ even when presenting poor dental health. ${ }^{32,33}$ In addition, these individuals generally have a misknowledge about the dark discoloration that cavities might present and the appropriate treatment. Thus, some people might believe that performing tooth bleaching would improve their oral health and increase attractiveness. ${ }^{5}$

A higher prevalence of dental bleaching was found in individuals who declared to have visited the dentist less than one year before the interview. This might have been found because of dentists offering this type of treatment, even for patients that have no complaints about tooth color. In fact, the dentist suggestion for treatments can induce the patient to perform them. However, the type of service was not associated with this outcome, which indicates that seeing a dentist regularly can be a decisive factor for performing tooth bleaching, regardless of type of service used. Visiting the dentist at least once a year could indicate a greater concern about oral health and esthetics, ${ }^{34}$ even in those who access public dental services, where professional tooth bleaching is not offered. Frequent dental visits could promote a greater knowledge about treatments and consequently motivate the search for alternatives, 
which can vary from professional tooth bleaching to treatments with OTC products.

It is known that many factors can cause teeth pigmentation, such as strongly colored foods and drinks, and smoking. Previous studies showed that smokers present a higher dissatisfaction with tooth color, which compromises dental esthetics. ${ }^{3,35}$ In the present study, a $60 \%$ higher prevalence of having undergone tooth bleaching was found in individuals with smoking habits at 30 years. This could be because greater dental pigmentations are observed in smokers. A recent clinical trial evaluated at-home dental whitening in smokers and non-smokers and found differences between groups only before performing clinical dental prophylaxis. ${ }^{36}$ After prophylaxis, teeth color did not presented significant differences. Thus, even if these pigmentations are extrinsic, they cause a significant change on the perception of tooth coloration, which can lead individuals to search for dental bleaching to increase their satisfaction with tooth color.

Among subjective measures of self-perception, tooth color perception was the only one associated with the desire for bleaching treatment. Individuals who reported being dissatisfied with the color of their teeth showed a higher desire of perform dental bleaching. Moreover, they also performed more dental whitening, proving that the main reason that motivates people to search for bleaching treatment is the perception of dark teeth, as suggested by other authors. ${ }^{3}$ This probably occurred because these individuals are more worried about their teeth color, and consequently are trying to look for alternatives to improve their appearance.

Important points should be highlight about the present study. The population-based sample confers external validity to our findings. Furthermore, young adults are the potential target of dental bleaching, due to the demand for esthetics in this population. Therefore, studies including elders can underestimate the results since the requirements in relation to esthetics are lower in this age group. ${ }^{7}$ Also, a multidisciplinary cohort design allows collecting behavioral and socioeconomic variables with precision, such as smoking habits and socioeconomic status in several moments of the life course. On the other hand, some limitation should be highlighted. Using a questionnaire to assess the outcomes could lead to an overestimation of the results, especially regarding prevalence of treatment, since individuals could interpret tooth bleaching as any method to white their teeth, including those considered ineffective, such as the use of dentifrices. ${ }^{37}$

Another point to consider is that individuals who have never considered dental bleaching could answer "yes" to the question of desire for treatment when this option is offered to them, producing an overestimated result. However, this outcome was evaluated similarly in other studies.,38

\section{Conclusion}

The present findings confirm that tooth bleaching has become a frequently desired dental treatment to improve dental esthetics and a considerable proportion of adults has performed the treatment. Our results suggest that variables related to regular visits at the dentist, smoking habit and self-perception with dental color, act as a major factors for wishing or having performed dental bleaching. In addition, income and caries trajectories were strongly associated with desire to perform dental bleaching, showing that experiences in the life course influence oral health outcomes.

\section{References}

1. Geus JL, Wambier LM, Kossatz S, Loguercio AD, Reis A. At-home vs In-office Bleaching: A Systematic Review and Meta-analysis. Oper Dent. 2016 Jul-Aug;41(4):341-56. https://doi.org/10.2341/15-287-LITP

2. Carey CM. Tooth whitening: what we now know. J Evid Based Dent Pract. 2014 Jun;14 Suppl:706. https://doi.org/10.1016/i.jebdp.2014.02.006
3. Alkhatib MN, Holt R, Bedi R. Prevalence of self-assessed tooth discolouration in the United Kingdom. J Dent. 2004 Sep;32(7):561-6. https://doi.org/10.1016/i.jdent.2004.06.002

4. Tin-Oo MM, Saddki N, Hassan N. Factors influencing patient satisfaction with dental appearance and treatments they desire to improve aesthetics. BMC Oral Health. 2011 Feb;11(1):6. https://doi.org/10.1186/1472-6831-11-6 
5. Fernández E, Bersezio C, Bottner J, Avalos F, Godoy I, Inda $\mathrm{D}$ et al. Longevity, esthetic perception, and psychosocial impact of teeth bleaching by low (6\%) hydrogen peroxide concentration for in-office treatment: a randomized clinical trial. Oper Dent. 2017 Jan/Feb;42(1):41-52. https://doi.org/10.2341/15-335-C

6. Meireles SS, Goettems ML, Dantas RV, Bona AD, Santos IS, Demarco FF. Changes in oral health related quality of life after dental bleaching in a double-blind randomized clinical trial. J Dent. 2014 Feb;42(2):114-21. https://doi.org/10.1016/i.jdent.2013.11.022

7. Bruhn AM, Darby ML, McCombs GB, Lynch CM. Vital tooth whitening effects on oral health-related quality of life in older adults. J Dent Hyg. 2012;86(3):239-47.

8. Montenegro-Arana A, Arana-Gordillo LA, Farana D, Davila-Sanchez A, Jadad E, Coelho U et al. Randomized double-blind clinical trial of bleaching products in patients wearing orthodontic devices. Oper Dent. 2016 Jul-Aug; 41 (4):379-87. https://doi.org/10.2341/15-240-C

9. Meireles SS, Santos IS, Bona AD, Demarco FF. A double-blind randomized clinical trial of two carbamide peroxide tooth bleaching agents: 2-year follow-up. J Dent. 2010 Dec;38(12):956-63. https://doi.org/10.1016/j.jdent.2010.08.003

10. Joiner $A$. The bleaching of teeth: a review of the literature. J Dent. 2006 Aug;34(7):412-9. https://doi.org/10.1016/i.jdent.2006.02.002

11. Hasson H, Ismail Al, Neiva G. Home-based chemically-induced whitening of teeth in adults. Cochrane Database Syst Rev. 2006 Oct;(4):CD006202. https://doi.org/10.1002/14651858.CD006202

12. Meireles SS, Heckmann SS, Leida FL, Santos IS, Della Bona A, Demarco FF. Efficacy and safety of $10 \%$ and 16\% carbamide peroxide tooth-whitening gels: a randomized clinical trial. Oper Dent. 2008 Nov-Dec;33(6):606-12. https://doi.org/10.2341/07-150

13. Demarco FF, Conde MC, Ely C, Torre EN, Costa JR, Fernández MR et al. Preferences on vital and nonvital tooth bleaching: a survey among dentists from a city of southern Brazil. Braz Dent J. 2013 Sep-Oct;24(5):527-31. https://doi.org/10.1590/0103-6440201302152

14. Moncada G, Sepúlveda D, Elphick K, Contente M, Estay J, Bahamondes $V$ et al. Effects of light activation, agent concentration, and tooth thickness on dental sensitivity after bleaching. Oper Dent. 2013 Sep-Oct;38(5):467-76. https://doi.org/10.2341/12-335-C

15. Vieira-Junior WF, Lima DA, Tabchoury CP, Ambrosano GM, Aguiar FH, Lovadino JR. Effect of Toothpaste Application Prior to Dental Bleaching on Whitening Effectiveness and Enamel Properties. Oper Dent. 2016 Jan-Feb;41(1):E29-38. https://doi.org/10.2341/15-042-LPMID:26449589

16. Dalazen CE, De Carli AD, Bomfim RA, Dos Santos ML. Contextual and individual factors influencing periodontal treatment needs by elderly brazilians: a multilevel analysis. PLoS One. 2016 Jun;11(6):e0156231. https://doi.org/10.1371/journal.pone.0156231

17. Cabral ED, Caldas AF Jr, Cabral HA. Influence of the patient's race on the dentist's decision to extract or retain a decayed tooth. Community Dent Oral Epidemiol. 2005 Dec;33(6):461-6. https://doi.org/10.1111/j.1600-0528.2005.00255.x

18. Wulfman C, Tezenas du Montcel S, Jonas P,

Fattouh J, Rignon-Bret C. Aesthetic demand of French seniors: a large-scale study. Gerodontology. 2010 Dec;27(4):266-71. https://doi.org/10.1111/j.1741-2358.2009.00331.x

19. Victora CG, Barros FC. Cohort profile: the 1982 Pelotas (Brazil) birth cohort study. Int J Epidemiol. 2006 Apr;35(2):237-42. https://doi.org/10.1093/ije/dyi290

20. Horta BL, Gigante DP, Gonçalves H, Motta JS, Mola CL, Oliveira IO et al. Cohort profile update: the 1982 Pelotas (Brazil) birth cohort study. Int J Epidemiol. 2015 Apr;44(2):44le. https://doi.org/10.1093/ije/dyv017

21. Jones B, Nagin D, Roeder K. A SAS procedure based on mixture models for estimating developmental trajectories. Sociol Methods Res. 2001;29(3):374-93. https://doi.org/10.1177/0049124101029003005

22. Dennis JE Jr, Gay DM, Welsch RE. An adaptive nonlinear least-squares algorithm. ACM Trans Math Softw. 1981;7(3):348-68. https://doi.org/10.1145/355958.355965

23. Jones B, Nagin D. Advances in group-based trajectory modeling and an SAS procedure for estimating them. Sociol Methods Res. 2007;35(4):542-71. https://doi.org/10.1177/0049124106292364

24. Barros AJ, Hirakata VN. Alternatives for logistic regression in cross-sectional studies: an empirical comparison of models that directly estimate the prevalence ratio. BMC Med Res Methodol. 2003 Oct;3(1):21. https://doi.org/10.1186/1471-2288-3-21

25. Edmonds A, Sanabria E. Medical borderlands: engineering the body with plastic surgery and hormonal therapies in Brazil. Anthropol Med. 2014;21(2):202-16. https://doi.org/10.1080/13648470.2014.918933

26. Serraglio CR, Zanella L, Dalla-Vecchia KB, RodriguesJunior SA. Efficacy and safety of over-the-counter whitening strips as compared to home-whitening with $10 \%$ carbamide peroxide gel:systematic review of RCTs and metanalysis. Clin Oral Investig. 2016 Jan;20(1):114. https://doi.org/10.1007/s00784-015-1547-8

27. Luque-Martinez I, Reis A, Schroeder M, Muñoz MA, Loguercio AD, Masterson D et al. Comparison of efficacy of tray-delivered carbamide and hydrogen peroxide for at-home bleaching: a systematic review and meta-analysis. Clin Oral Investig. 2016 Sep;20(7):1419-33. https://doi.org/10.1007/s00784-016-1863-7

28. Montero J, Gómez-Polo C, Santos JA, Portillo M, Lorenzo MC, Albaladejo A. Contributions of dental colour to the physical attractiveness stereotype. J Oral Rehabil. 2014 Oct;41(10):76882. https://doi.org/10.1111/joor.12194 PMID:24905467 
Desire for tooth bleaching and treatment performed in Brazilian adults: findings from a birth cohort

29. Oliveira RF, Souza JG, Haikal DS, Ferreira EF, Martins AM. Equity in the use of dental services provided by the Brazilian Unified Health System (SUS) among the elderly: a populationbased study. Cien Saude Colet. 2016 Nov;21 (11):3509-23. https://doi.org/10.1590/1413-812320152111.22532015

30. Nicoll KL, Phillips E, Shaefer HL, Simoncic T. Low-income parents' perceptions of oral health and acceptance of mid-level dental providers. J Dent Hyg. 2016 Apr;90(2):100-10.

31. Edelstein BL. Disparities in oral health and access to care: findings of national surveys. Ambul Pediatr. 2002 Mar-Apr;2(2 Suppl):141-7. https://doi.org/10.1367/15394409(2002)002<0141:DIOHAA > 2.0.CO;2

32. Azofeifa A, Yeung LF, Alverson CJ, Beltrán-Aguilar E. Dental caries and periodontal disease among U.S. pregnant women and nonpregnant women of reproductive age, National Health and Nutrition Examination Survey, 1999-2004. J Public Health Dent. 2016 Sep;76(4):320-9. https://doi.org/10.1111/iphd.12159

33. Correa MB, Peres MA, Peres KG, Horta BL, Barros AJ, Demarco FF. Do socioeconomic determinants affect the quality of posterior dental restorations?
A multilevel approach. J Dent. 2013 Nov;41(11):960-7.

https://doi.org/10.1016/i.jdent.2013.02.010

34. Dudea D, Lasserre JF, Alb C, Culic B, Pop Ciutrila IS, Colosi H. Patients' perspective on dental aesthetics in a South-Eastern European community. J Dent. 2012 Jul;40 Suppl 1:e7281. https://doi.org/10.1016/i.jdent.2012.01.016

35. Alkhatib MN, Holt RD, Bedi R. Smoking and tooth discolouration: findings from a national crosssectional study. BMC Public Health. 2005 Mar;5(1):27. https://doi.org/10.1186/1471-2458-5-27

36. Geus JL, Lara MB, Hanzen TA, Fernández E, Loguercio AD, Kossatz $\mathrm{S}$ et al. One-year follow-up of at-home bleaching in smokers before and after dental prophylaxis. J Dent. 2015 Nov;43(11):1346-51. https://doi.org/10.1016/i.jdent.2015.08.009

37. Torres CR, Perote LC, Gutierrez NC, Pucci CR, Borges $A B$. Efficacy of mouth rinses and toothpaste on tooth whitening. Oper Dent. 2013 Jan-Feb;38(1):57-62. https://doi.org/10.2341/11-360-L

38. Priest G, Priest J. Promoting esthetic procedures in the prosthodontic practice. J Prosthodont. 2004 Jun;13(2):111-7. https://doi.org/10.1111/j.1532-849X.2004.04017.x 